Article

\title{
Virtual Exchange to Develop Cultural, Language, and Digital Competencies
}

\author{
Said Machwate $^{1\left(\mathbb{D}, \text { Rachid Bendaoud }^{1}\left(\mathbb{D}, \text { Juergen Henze }^{2}\left(\mathbb{D}, \text { Khalid Berrada }^{3, *} \text { and Daniel Burgos }\right.\right.\right.}{ }^{4, *}$ \\ 1 Trans ERIE, Faculté des Sciences Semlalia, Cadi Ayyad University, Marrakesh 40000, Morocco; \\ s.machwate@uca.ma (S.M.); bendaoud@uca.ma (R.B.) \\ 2 Department of Education Studies, Humboldt-Universität zu Berlin, 10099 Berlin, Germany; \\ juergen.henze@hu-berlin.de \\ 3 Faculty of Sciences, Mohammed V University in Rabat, Rabat 10000, Morocco \\ 4 Research Institute for Innovation \& Technology in Education (UNIR iTED), Universidad Internacional de La \\ Rioja (UNIR), 26006 Logroño, Spain \\ * Correspondence: k.berrada@um5r.ac.ma (K.B.); daniel.burgos@unir.net (D.B.)
}

Citation: Machwate, S.; Bendaoud, R.; Henze, J.; Berrada, K.; Burgos, D. Virtual Exchange to Develop Cultural, Language, and Digital Competencies. Sustainability 2021, 13, 5926. https:// doi.org/10.3390/su13115926

Academic Editor: Petra Poulová

Received: 15 January 2021

Accepted: 21 May 2021

Published: 24 May 2021

Publisher's Note: MDPI stays neutral with regard to jurisdictional claims in published maps and institutional affiliations.

Copyright: (c) 2021 by the authors. Licensee MDPI, Basel, Switzerland. This article is an open access article distributed under the terms and conditions of the Creative Commons Attribution (CC BY) license (https:/ / creativecommons.org/licenses/by/ $4.0 /)$.

\begin{abstract}
Many researchers have underlined the benefits of student mobility in strengthening their communication skills. Studying a foreign language and fostering knowledge about behavioural attitudes are the most common research cases. One of the major issues of mobility, by its very nature, is that it implies significant travel and accommodation costs. Virtual mobility, or Virtual Exchange (VE), can be introduced as a proactive alternative solution. This work presents an evaluation of a telecollaborative online course model organised as a VE between German and Moroccan universities. It was established to explore the benefits of integrating a VE experience by practicing some 21stcentury knowledge elements as tools for the development of intercultural, language, and digital competencies from the perspective of mobility. In this paper, we present a VE model and its design, structure, and progress. Then, we evaluate this first experience to overcome some challenges that similar future experiences could face. We analyse the tools proposed in this design, the interactions between the different actors, and their feedback. The evaluative study shows the acquisition of awareness of cultural differences and the improvement of language skills through practice in addition to the development of some digital skills.
\end{abstract}

Keywords: online learning; virtual exchange model; cultural skills; digital skills; language skills; telecollaboration

\section{Introduction}

In the last few decades, globalization has led to massive growth in mobility for economic [1], scientific, and learning purposes [2,3]. Knowing the other creates an atmosphere favourable to exchange and negotiation, building mutual relations based on trust and empathy, and avoiding conflicts [4]. The 2030 Agenda for Sustainable Development pledges to foster intercultural understanding, tolerance, mutual respect, and an ethic of global citizenship and shared responsibility [5].

The World Economic Forum states that 21st-century skills shape students' lifelong learning, as illustrated in Figure 1. It particularly mentions how students can apply core skills to everyday tasks and how they can approach complex challenges and their changing environment [6]. Furthermore, cultural programs would be very profitable for fostering economic and sustainable outcomes in cross-cultural trading [7,8].

With the emergence of Information and Communication Technologies (ICT), people started to feel cultural and communicational gaps between different populations, even when speaking the same language or studying/working in the same field but in distant locations. As telecollaboration involves people from different backgrounds, it is difficult to achieve learning goals for a common ground [9]. Friedrichs stated that cultural behaviours 
are different even from region to region in the same country [10]. As another example, due to diverse cultural backgrounds, different social behaviours could affect the development of teacher/learner interactions or even the collaborative work in a learning process. Online teachers and moderators should be aware that there is no opposition between the social/cultural interaction and the learning processes [11]. This reflection is greatly apparent in the learning process with students and teachers from distant countries and of different cultures.
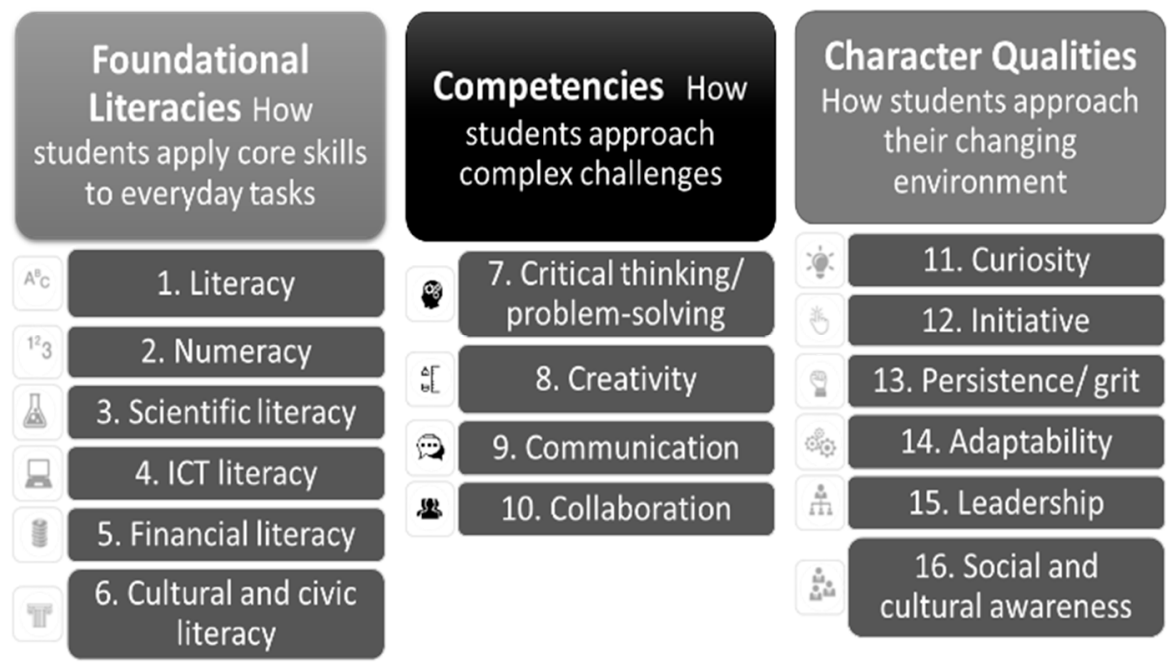

Figure 1. The 16 skills required for the 21st century.

Within the framework of its international comparative school performance measurements, the OECD has also been intensively concerned since 1998 with the question of which competencies, in particular core or key competencies, are necessary for a "successful life and a well-functioning society" [12-14]. The project developed around this question operated under the name Definition and Selection of Competencies: Theoretical and Conceptual Foundations (DeSeCo for short) and was directly related to the internationally highly influential Programme for International Student Assessment (PISA). In detail, the DeSeCo project distinguishes three main categories of key competencies: (1) acting in socially heterogeneous groups, (2) the autonomous ability to act and create, and (3) the interactive use of media and tools. The project was intended to define some core competencies for a successful living in the 21st century (however this may be defined), under the sign of competitive globalization, and it provided the template for the well-known PISA study.

To this end, the PISA study for 2018 for the first time introduced the category of "Global Competence" as a cross-curricular multidimensional domain of school curricula. The Global Competence links familiar strands of discourse on intercultural competence development and intercultural learning, quite in line with similar considerations by the Council of Europe and UNESCO. The definition of global competence is reminiscent of that of intercultural competence, especially in the field of intercultural learning ([13], p. 4).

Global competence is the capacity to analyse global and intercultural issues critically and from multiple perspectives, to understand how differences affect perceptions, judgments, and ideas of self and others, and to engage in open, appropriate, and effective interactions with others from different backgrounds on the basis of a shared respect for human dignity.

Virtual Exchange (VE) is an online program conceived to respond to the growing need for collaborating and/or studying with people from different cultural backgrounds. Matching with the objectives of the World Economic Forum as well as with the abovementioned OECD concept of Global Competence, in terms of improving 21st-century skills, the main characteristics of VE are the development of foreign language competence, intercultural skills, and digital literacy $[15,16]$. Furthermore, VE is a telecollaboration online 
course/training that copes with the inability to offer physical mobility for every demand. It aims to offer the same benefits as mobility but remotely/online [17].

Many researchers have been interested in learning about productive options and possible challenges for running similar experiences [18]. Due to global scientific mobility [2], VE has shown valuable contributions to strengthening foreign learners' language intercultural and electronic competencies, in separate cases, but for almost all scientific fields to overcome integration barriers at the host university [19].

In this paper, we describe the design of a VE model for improving language, digital, and cultural skills. We present how it has been conducted, its outcomes, and what to take into account for a future similar experience.

\section{Erasmus+ Virtual Exchange}

Erasmus+ Virtual Exchange is part of the Erasmus+ programme. It has two main objectives: to promote the development and integration of telecollaborative research and practice across all disciplines and subject areas in higher education and to actively engage in raising awareness of telecollaboration and VE at the institutional and policy-making level. It aims to expand the reach and scope of the Erasmus+ programme through VEs, which are technology-enabled people-to-people dialogues sustained over a period of time [20].

VE distinguishes itself from other forms of online learning in several ways [21]:

- People-to-people interaction and dialogue.

- The learning goals include soft skills such as the development of intercultural awareness, digital literacy, group work, communication, language competency, etc.

- Participants will be seeking mutual understanding and co-creating knowledge, based on their own experiences.

- VE programs explicitly address intercultural understanding and engaging with difference.

\section{Theoretical Background}

Today, the mobility of students is taken highly into account. In 2018, for example, 52,500 Moroccan students were in mobility, and 22,096 from other countries were hosted by Morocco. In Germany, 122,538 students went on mobility, while 311,738 foreign students were hosted in the country [22].

Intercultural learning is one of the objectives of student mobility. European ministers responsible for higher education from 29 European countries have declared student mobility as one of the main themes and commitments of the conferences held within the Bologna Process Implementation [23]. They refer to student mobility as a powerful means to enhance mutual understanding and to foster the employability of graduates. Student mobility has shown several advantages, from behavioural to linguistic development; for example, the Erasmus Programme showed that participants demonstrate that they are more open to international opportunities, which increases their chances and reinforces their advantages for employment in a globalised labour market [24].

To this end, the European Commission has allocated millions of euros to scientific and research programmes (such as Erasmus) for promoting mobility across Europe. The European Commission aims to assess the effects of inclusion and access to mobility on the one hand and employability and professional integration on the other. In France alone, for example, between 2014 and 2018, project leaders were funded on education and training components, for a cumulative budget of 729,084,195 euros [25]. On another side, cultural differences could alter the purpose of students' mobility. Multiple explanations have been advanced about the erosion of social bonds. One theory focuses on the decline of national identities due to social and cultural diversification associated with migration and a globalized economy [14].

The innovation challenge in higher education is to examine the unstated premises and the comfortable routines of academic life [26]. It becomes more important to workforce development to address the increased demand for higher education [27]. Therefore, edu- 
cational technology and online learning have become the pillars of the education of the 21st century and very particularly for ensuring education for sustainability [28,29].

VE and telecollaboration are innovative emerging practices in the field of online learning and teaching [30]. They have been used to develop foreign language skills in higher education. While mastering a language academically is not enough to communicate with it easily, many other components, such as the communicator's knowledge on the subject, multicultural competence, etc., are needed to gain communicative competence in a foreign language [31-33].

Intending to increase their financial profits, companies try to overcome cultural disparities in their transnational business [34], while in higher education, the emphasis is on language learning and the enrichment of cultural skills $[15,35,36]$. Thus, a link has been established between the needs of companies and those of universities in terms of teaching intercultural communication skills $[37,38]$. Effective communication requires the acquisition of appropriate cultural skills in situations of dialogue. Lack of these skills could lead to communication discomfort or conflicts and negotiation failures and could erode cooperation and collaboration. This has a direct impact on objectives, subjects, or bilateral performance. In situ, applying innovative practices would overcome these difficulties, especially in telecollaboration programs [39].

In the field of learning, ICT tools have been used to reduce communication gaps and foster foreign language learning and hence develop more language skills. The use of blogs, for example, helped to overcome communication gaps [40,41] but remained insufficient to resolve all the other related issues. From another point of view, developing solutions and implementing technology-mediated practices leads to the enrichment of the learning/teaching experience [42]. With the affordances of ICT and the wide use of Learning Management Systems (LMS), students may find a way to collaborate with foreign peers in small courses or training to overcome cultural, language, or digital barriers [43]. The collaboration processes constitute the hard part of an online learning system; it demands a large amount of preparation work comparing to in-class learning. Besides early preparing all the learning content, teachers are more likely to have to act as moderators, and learners become the main actors and beneficiaries in this new learning scheme [44]. As such, few models have been used to create a course with similar specific pedagogical objectives [45-47]. Today, the trends are more to use telecollaboration in cross-disciplinary approaches and the integration with other modes of education beneficiating from the emergence of videoconferencing for the online intercultural interaction [30].

Integration of telecollaboration as a tool to develop competencies related to language, digital, or culture was studied separately in several contexts and was faced by technological and/or pedagogical issues [46-48].

As it is defined, a competent person is identified as having sufficient skill, ability, knowledge, or training to act appropriately, whether in behaviour, words, or actions, in a particular context $[49,50]$. Competence deals with knowledge and its applications (cognitive and functional) on one side and behaviour and its guiding principles (personal and social) on the other side [51]. Based on this definition, the goal of this work is to describe the implementation of a course set pedagogically on VE practice, and study how the learners, at the end of this course, can improve (or acquire) some language, digital, and cultural competencies collaboratively and online.

\section{The Virtual Exchange Design}

The design of the VE studied in this paper was set after a training experience in the Erasmus+ VE. The authors describe how a course set in a VE model was designed, how it was conducted, its outcomes (see Figure 2), and the challenges to work on in further VEs. We evaluated the design according to learners' response degrees toward three competencies: intercultural, language, and digital. 


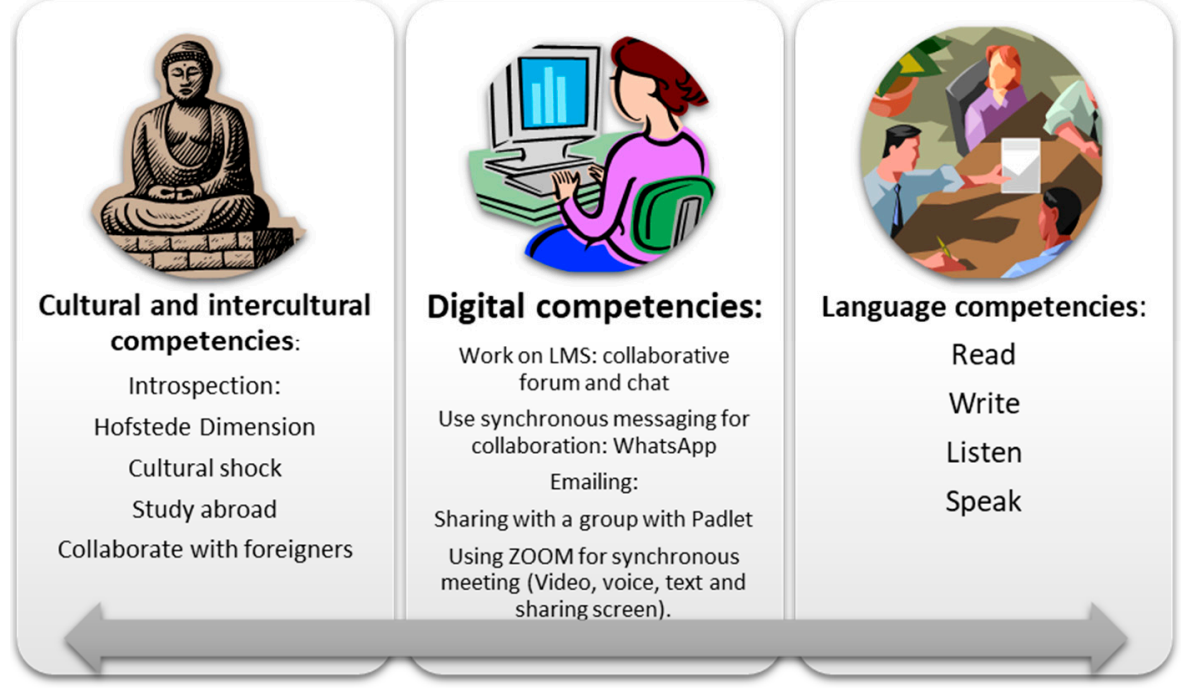

Figure 2. Learning outcomes of the Virtual Exchange.

\subsection{Course Description}

The course was produced as an application of the Collaborative TEP Design ADVANCED TEP Oct/Nov 2018 as part of the Advanced Training of Erasmus+ Virtual Exchange Programme. It was run between Cadi Ayyad University of Marrakesh (UCA) and Humboldt University of Berlin (HUB) for ten students (six from Morocco and four from Germany) and during a period of six weeks (from January to February 2019).

Regarding the selection of topics, it was decided that students should have academic and intellectual benefits in the long run, especially if they intended to continue their studies abroad. Therefore, the VE was called "Intercultural Competence Development for International Academic Mobility" and it covered a wide range of topics directly related to the student's research and teaching.

The course is a four-week journey to introduce key topics of intercultural communication in the sight of international mobility. It aims to achieve three main learning objectives: to define and evaluate topics to consider in an intercultural communication/interaction, to be able to communicate and collaborate with foreigners in English, and to be able to use some communication and collaborative digital tools.

In order to achieve these objectives, students had to work individually as well as in groups/teams to experience the challenge of diversity in virtual communication. Based on the introduction of some key paradigms of culture theory, participants were guided to come up with some kind of cultural introspection, gain an understanding of cultural differences, and collaborate virtually with foreigners in other languages and using technological tools.

Details for the expected activities were provided for each week (see Table 1).

As it was a new experience for both members of the pedagogical team, the adopted strategy was to supervise this course as an ongoing process. The team has pre-established a course timeline chart with all the activities, their objectives, the tasks, the tools needed, and the estimated workload for accomplishing the task. Each week, the course designers discussed and evaluated the completion of tasks, the difficulties encountered by students on various levels, and how to adapt the following week's content, tasks, and methods to achieve the week's objectives. Minor adjustments were made to the course timeline.

The course was structured in a way that offers the necessary tools to achieve the learning objectives. As such, measuring the outcomes of the course was a continuous process. Qualitative, quantitative, and observable parameters were measured continuously. 
Table 1. Course structure.

\begin{tabular}{|c|c|c|c|}
\hline Week & Activity & Objectives & Tools \\
\hline 0: Welcome & $\begin{array}{l}\text { Log on to the course and fill in } \\
\text { profile information }\end{array}$ & $\begin{array}{l}\text { Create a space of trust between } \\
\text { learners } \\
\text { Check any difficulties in accessing } \\
\text { the course }\end{array}$ & $\begin{array}{l}\text { Moodle profile } \\
\text { Email }\end{array}$ \\
\hline $\begin{array}{l}\text { 1: Know one's cultural } \\
\text { background }\end{array}$ & $\begin{array}{l}\text { Share pictures and comments } \\
\text { Visualise video }\end{array}$ & $\begin{array}{l}\text { Break the ice and create an } \\
\text { atmosphere of trust } \\
\text { Initiate students in cultural } \\
\text { baggage } \\
\text { Use of new communication tool }\end{array}$ & $\begin{array}{l}\text { Moodle Forum } \\
\text { Visualizing video } \\
\text { Padlet } \\
\text { ZOOM }\end{array}$ \\
\hline 2: Cultural introspection & $\begin{array}{l}\text { Lecture } \\
\text { Questionnaire } \\
\text { Discussion }\end{array}$ & $\begin{array}{l}\text { Stimulate cultural differences } \\
\text { based on introspection culture } \\
\text { Find a partner to work with } \\
\text { Position one's cultural behaviour }\end{array}$ & $\begin{array}{l}\text { PDF } \\
\text { Padlet } \\
\text { Zoom } \\
\text { Email }\end{array}$ \\
\hline $\begin{array}{l}\text { 3: Greet Hofstede cultural } \\
\text { dimensions }\end{array}$ & $\begin{array}{l}\text { Lecture } \\
\text { Collaborative work } \\
\text { Discussion }\end{array}$ & $\begin{array}{l}\text { Summarise Hofstede cultural } \\
\text { dimensions } \\
\text { Formulate opinions from the } \\
\text { cultural background }\end{array}$ & $\begin{array}{l}\text { Moodle forum } \\
\text { Email (and WhatsApp) } \\
\text { Zoom }\end{array}$ \\
\hline $\begin{array}{l}\text { 4: Developing topics of } \\
\text { interest revealed by learners }\end{array}$ & $\begin{array}{l}\text { Lectures for each need } \\
\text { Discussion }\end{array}$ & $\begin{array}{l}\text { Discuss, by collaborating, one } \\
\text { topic on the Hofstede cultural } \\
\text { model }\end{array}$ & $\begin{array}{l}\text { Forum } \\
\text { Email } \\
\text { ZOOM }\end{array}$ \\
\hline 5: What is next? & Open discussion & $\begin{array}{l}\text { Summary and preparation for } \\
\text { getting a badge }\end{array}$ & $\begin{array}{l}\text { Zoom } \\
\text { Forum } \\
\text { WhatsApp }\end{array}$ \\
\hline
\end{tabular}

\subsection{The Pedagogical Design Based on ADDIE and the Five-Stage Framework}

As a dynamic course, the VE design depends on the learners' responses during the week, so we have chosen the ADDIE framework [52] to construct this course model. It is an instructional design model that follows a systematic approach to the analysis, design, development, implementation, and evaluation of learning materials and activities (see Figure 3). Therefore, it permits us to easily adjust the content due to the interactive aspect of the course.

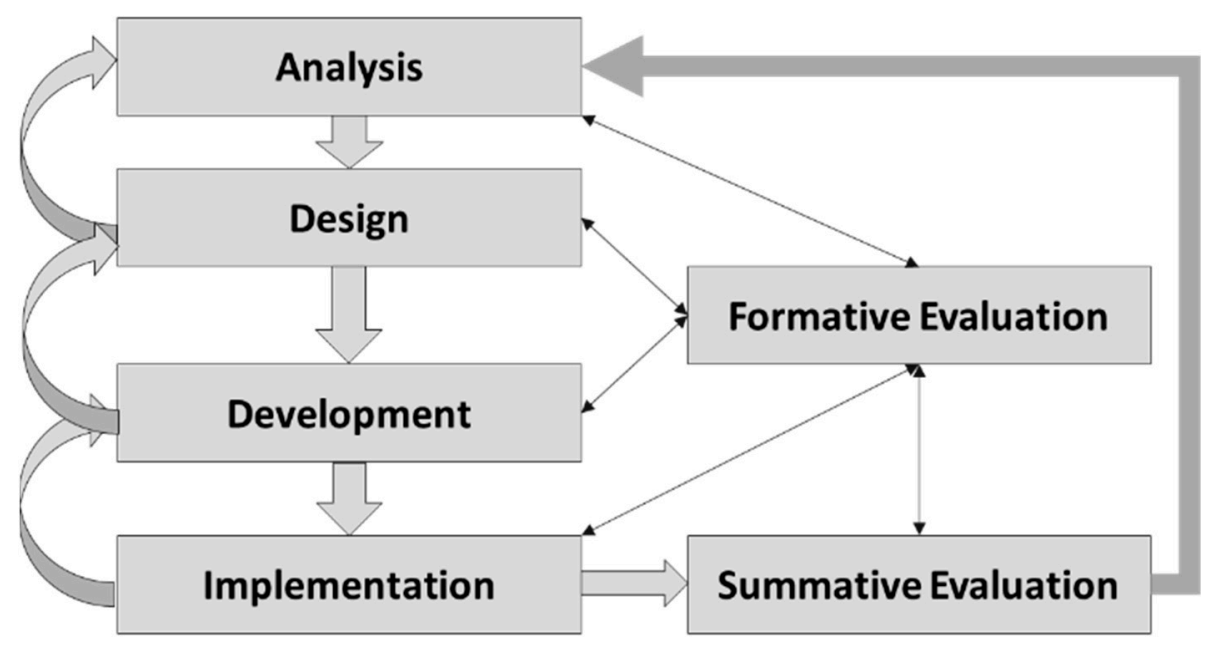

Figure 3. ADDIE instructional design.

As far as the organization of virtual cooperation throughout the course is concerned, Gilly Salmon's five-stage framework was adopted as a process model [53]. This model assumes five stages of interconnected learning realms that can be mapped as an ongoing 
process comprising (1) "access and information", (2) "online socialization", (3) "information exchange", (4) "knowledge construction", and (5) "development". For each stage, the necessary technical and pedagogical prerequisites for a successful virtual collaboration and learning have been identified:

"In summary, the five-stage model provides an example of how participants can benefit from increasing skill and comfort in working, networking, and learning online, and what $e$-moderators need to do at each stage to help them to achieve this success. The model shows how to motivate online participants, to build learning through appropriate e-tivities, and to pace e-learners through programmes of training and development. Individual access and the induction of participants into online learning are essential prerequisites for online conference participation (stage 1, at the base of the flights of steps). Stage 2 involves individual participants establishing their online identities and then finding others with whom to interact. At stage 3, participants engage in mutual exchange of information. Up to and including stage 3, a form of co-operation occurs whereby each person supports the other participants' goals. At stage 4, course-related group discussions develop and the interaction becomes more collaborative. At stage 5, participants look for more benefits from the system to help them achieve personal goals and reflect on the learning processes." ([53], p. 11)

The overall course structure followed this concept of five-stage framing and has been well received by all participants (see Table 1 ).

\subsubsection{Analysis}

The analysis of needs shows that students should have academic and intellectual benefits in the long run, especially if they intend to go abroad to study or work. The course would help students to gain some specific competencies to prepare them for this purpose. An Erasmus+ European programme of supporting mobility across Europe and between Europe and the Mediterranean region showed that students were greatly willing to participate in mobility programs [25].

\subsubsection{Design}

The course team was composed of a German professor specialising in comparative education who teaches culture and interculturality, and a Moroccan pedagogical engineer who is in charge of setting up the instructional design of the course and support teachers and students in technical matters (LMS, Zoom, emailing, etc.). Many emails and online synchronous meetings (six hours) were exchanged between the course team to establish this course.

One of the greatest challenges was to draft the learning objectives in a detailed format as shown above, simply because people (in both Berlin and Marrakesh) normally do not work like that in their departments. The course objectives are defined by the university departments or by the Ministry of Higher Education. Certainly, one of the greatest learning experiences was to reflect on objectives more consciously than ever.

The overall objectives were developed as:

1. Students will be able to define and evaluate core elements / perspectives of intercultural communication/interaction in an international exchange,

2. They will be able to communicate and collaborate effectively in diverse cultural environments (working with others from different countries), and

3. They will be able to use a variety of technological tools to communicate and complete tasks in the VE.

A good piece of the adopted strategy was to prepare the content in sequential order, starting with less reading material and less demanding effort and proceeding to a higher level of reading and reflection. It took about two months of collaborative pre-work between the course constructors to draft a timeline for the four-week course and justify the selection of materials and the intensity of each week. In contrast to regular face-to-face class sessions, 
the teacher has to anticipate students' levels of competence/performance and understand their willingness to cope with requests within a week.

\subsubsection{Development}

As described in Table 1, the course is constructed based on weekly activities. These are set in different ways depending on the objective of each week. Synchronous and/or asynchronous discussions, collaborative work, readings, writings, and other exercises are used in many ways depending on the week's pedagogical objectives.

\subsubsection{Implementation}

"Week 0 " is inserted at the beginning of the course to introduce students to the objectives of the course, complete their profile information, and resolve any technical issues due to registration.

Instructions are given on the Moodle platform at the beginning of each week as well as by email to remind students of the tasks they should complete. Moreover, WhatsApp permits instant messaging for transmitting instructions, monitoring, and tutoring the learners.

Synchronous meetings via Zoom are set for every Tuesday at 8:00 p.m., as Marrakesh and Berlin are in the same time zone. These meetings mark the end of the week's activities and are used to project the work needed for the following week.

Activities are adapted depending on the students' responses and involvement. Some of the students may be more interested in certain topics than others, so the tasks are adapted accordingly.

Activities alternate from posting on the platform or in Padlet, returning individual or group documents, commenting, and discussing during the Zoom meetings.

\subsubsection{Evaluation (Assessment)}

Individual and group works are assessed by the end of each week. The synchronous sessions are used to discuss the accomplishment of the activities and measure the participation of the learners.

At the end of the VE, badges are awarded to students who had actively participated in the course, participated in at least one synchronous Zoom session, and attended the final synchronous session with the UNICollaboration facilitation team, which is a session with third-party facilitators qualified by Erasmus+ Virtual Exchange. The evaluation mainly concerns the acquisition of cultural competencies.

\section{Research Methodology}

This study is set as evaluative research of a new pedagogical experience [54], particularly as a "design-oriented evaluative research". This form of research to improve a programme or device is usually done during the action to allow a better fit to the ends sought. It appeals to people outside the design and implementation of the action but can also mobilize actors who take an active part in the action. When evaluative research concerns the development of tools or programs, generally it is referred to as "research design" ([54], p. 272).

It describes the way that the VE model was designed and applied, its strengths and weaknesses, and the possibilities to be developed in future experiences. As the researchers are at the core of the experience (two of the authors), they deal with interacting parameters that determine the way data is collected and interpreted, even qualitatively and/or quantitatively. The researchers were part of the experiment and could not stand apart from the course sequence, they were also "unstructured observers" collecting all observations that could bring more pieces of information than structured observations [55]. This mix is due to the number and complexity of variables in the experience [56]. For example, the parameter of communicative complexity on its own in an educational community is one of the most complex components for the implementation of information activities in 
a higher education community [57]. From another point of view, the establishment of a pre-research project and its implementation could alter the results of the study and may have a negative impact on the experience of the learners in the virtual exchange and modify their perception of the objectives intended at the beginning of the course [58,59].

In this work, data were collected continuously, mainly by unstructured observations of attitudes, the accomplishment of the activities, interchanges, and face expressions (onscreen). Each week, observations were made on the accomplishment of the activities, the discussions on the WhatsApp group, and Zoom. A comparison was made between each week's course to evaluate the improvement of the knowledge about the different topics of the course and the acquisition of the competencies expected.

In our case, we analysed data observed and collected from discussions in the WhatsApp messaging group (25 pages of text), discussions during Zoom synchronous meetings $(4 \mathrm{~h})$, discussions on the forum, and the completion of activities on the Padlet wall ( 2 walls) or exchanged by emails (Table 1 ).

That is how we started an evaluation of the responsiveness of the participants, their involvement degree in the synchronous or asynchronous collaboration work (motivation), their communication and language skills, their behaviours, and their use of digital tools in the whole process.

The different inter-linked data were continuously observed and measured. The process of instruction and learning being complementary and centred on the course objectives, we separated the analysis into three categories, each of which is related to the objective of the VE model.

\section{Results and Discussions}

In this section, we present and discuss the key elements of each of the three categories and we give some results.

\subsection{Language Competencies}

Students were informed before registering for the course that it would be held in English and that they should have a good command of this language in all aspects: reading, writing, listening, and speaking.

The practice of English was introduced gradually. It began with small text readings and writings followed by a short video and then practicing by hearing and speaking in the synchronous video sessions.

We made the following observations:

In many situations in this VE, we observed that the students had difficulties expressing themselves, both in speaking and writing. For example, during the second Zoom meeting, one participant said:

"My mind is not so fast with English words (.), I experience that my mind is practicing and now I begin to save words." (Darina)

Another student found it interesting to practice English with other students and that it was an enriching experience, and by the final week Zoom session, students admitted that the course helped them to practice their English live. They confessed that studying and collaborating in English is very different from just studying English as a foreign language.

"The course was very interesting (.) and we develop our way of communicating." (Rihab)

When it comes to writing in English, the overall language structures are mostly correct with very few grammatical mistakes. In the Padlet tool (two activities), activities on Moodle (forums), and emails (two activities), the offline time assigned to writing and the correction tools on the text software used, in addition to the nature of the homework done collaboratively, might be the elements that led to this finding.

On the other hand, mistakes occurred when the WhatsApp instant messaging tool was used. This may have been due to the nature of the tool as a casual/ informal instant 
messaging app. Moreover, sentences of impressions or expressions were very often replaced by emoticons.

Tjasa: Thank you everyone! It was a pleasure to meet you

Kenza: It was amazing to talk with $u$ all guys

Darina: (ㅇ) (-):(-)

Darina: It was funny to hear the voices

In the first Zoom synchronous meeting, students asked the instructors many times to repeat their sentences. We argue that listening was another language skill that was developed, especially by the final two sessions in which this request was no longer made.

To sum up, the course design helped the participants to improve their language skills. By the end of the course, they were able to read and write long documents with minor grammatical mistakes, and they were able to speak and debate ideas more fluently. We admit that practicing their English in this virtual environment improved their knowledge of English and thus their language competence.

\subsection{Digital Competencies}

The course has an online and collaborating learning structure that allows students to collaborate and communicate using ICT tools. They use specific digital tools at each course stage to fulfil the VE objectives. We observe and measure their usage of these tools and their application during the whole course process.

The tools are selected to attain the targeted digital competencies. These are defined by the European Digital Competence Framework for Citizens as the "competencies needed to use digital technologies in a confident, critical, collaborative and creative way to achieve goals related to work, learning, leisure, inclusion, and participation in the digital society" [60].

The design of the course aims to make students familiar with these new tools so they can use them in future collaborations or training. This will lead to obtaining needed digital competencies in collaboration, communication, learning, seeking information, digital content creation, and so on.

The Moodle platform is a Learning Management System (LMS). It is a structured environment used for running and mediating the course. The other digital tools were used with respect to their affordance and the activity objective, as described in Table 2.

Table 2. Digital tools of the VE.

\begin{tabular}{lll}
\hline Tool & Affordances & Objectives \\
\hline Moodle & $\begin{array}{l}\text { Structure and course design } \\
\text { Collaborate through forum } \\
\text { Communicate } \\
\text { Resources depository }\end{array}$ & $\begin{array}{l}\text { Centralise and organise instructions, } \\
\text { information, activities, and resources } \\
\text { Collaborate } \\
\text { Track and assess students (for instructors) }\end{array}$ \\
\hline Padlet & $\begin{array}{l}\text { Communicate to a group and establish } \\
\text { storyboards }\end{array}$ & Share, express opinions, and post feedback \\
\hline Email & $\begin{array}{l}\text { Asynchronous communication } \\
\text { Returning work } \\
\text { Depository }\end{array}$ & $\begin{array}{l}\text { Instruction } \\
\text { Send and/or exchange reports }\end{array}$ \\
\hline Zoom & Videoconferencing tool & $\begin{array}{l}\text { Communicate, exchange, debate, orient } \\
\text { (participants by instructors or between } \\
\text { participants themselves) }\end{array}$ \\
\hline WhatsApp group & Instant messaging & Prepare collaboration, tutor, help desk \\
\hline
\end{tabular}


By the end of the course, we observed that:

- $10 / 10$ students accessed the platform, used Padlet, and participated in Zoom sessions at least two times.

- $10 / 10$ students exchanged emails and produced documents.

- $\quad 9 / 10$ students used Padlet, shared texts and images, and commented to others.

- $\quad 9 / 10$ students participated actively by completing major activities on Moodle.

- $10 / 10$ students participated in the WhatsApp group, asking questions or responding to others.

In addition to these statistics, students expressed their satisfaction about learning to use new tools and how they will use them in the future.

"I figured out how to use Zoom on my own, which is a nice experience." (Andre)

"Tools like Padlet and Zoom have many benefits." (Kenza)

Monitoring and group discussions on WhatsApp facilitated the acquisition of these tools. Zoom and Padlet were tools that the participants had never used before, and by the end of the course, they were able to use them easily. One student created a Doodle link to organise synchronous work sessions. The other students found it to be a good tool to arrange their schedules when working in groups.

To sum up, bringing ICT into this VE is fundamental. Meanwhile, for digital competence acquisition purposes, these tools have to be used in a considered manner. In this section, the participants have to collaborate and communicate to learn using ICT.

We believe that by the end of the course, students were able to communicate, collaborate, create digital content, seek and share information, and even organise their time and work sessions remotely. We assume that they developed their digital competencies during this VE.

\subsection{Cultural and Intercultural Competencies}

The main objective of the course, from a cultural perspective, was to prepare students to understand cultural structures and intercultural challenges by introducing them to some key elements of intercultural communication in a possible international mobility prospect. This course aims at providing basic knowledge on the international approaches to understanding "culture" as shared living with/among social groups.

Based on the introduction of some key paradigms on culture theory, course participants are guided to come up with some kind of cultural introspection. In what ways should one see oneself as a recipient and a producer of culture at the same time? How does culture shape the communication and the way of interacting with and within different social collectives?

These perspectives are generated in highly interactive forms between all participants. The proposed VE model considered this interactivity to be an essential element in the course. Therefore, the model proposed activities for getting to know one another, building an atmosphere of trust [61], and reducing the social distance between the learners themselves and with the pedagogical team.

Participants were asked to create videos, narratives, or photos of various aspects of everyday life/interaction, share them with their peers, and comment on each other's submissions. These cultural artefacts can be used within different forms of VE and will form some kind of discourse among all participants, which might serve as a constant frame of reference for the entire period of the project.

Hence, the students were introduced to the intercultural Hofstede model [62], which shapes their behaviour in some way during the course. In this course, the theoretical model developed by Geert Hofstede, cultural dimensions, has been used, despite its wide international reputation as one possible approach for comparing cultures (nation-states). This form of value-based cultural analysis has been applied across disciplines, although the criticism of its methodological basis has been increasingly voiced internationally. Nevertheless, for students at the beginning of such a course, the Hofstede model of cultural 
dimensions is more likely to stimulate energetic cooperation and analysis than other more advanced approaches in social sciences and psychology.

In the following, we use this same model to describe how the students' behaviour was influenced during this virtual journey individually or collectively regarding each side of the Mediterranean. For each dimension of the Hofstede model, we present cases that illustrate the points observed during this four plus one-week journey.

\subsubsection{Differences between Small and Large Power Distance Societies}

A difference between Moroccan and German students was observed. The Moroccans believed that power is more centred in family, school, and the elderly, but the Germans saw this power as equally distributed in society.

When Moroccan students talked with their professors during the early Zoom meetings, they used more formal, formulated sentences to ask or express something, while the German students were more informal/casual in the way they spoke to the professors. By the end of the VE, the Moroccan students were more relaxed in expressing themselves, undoubtedly influenced by their German peers' attitudes towards the instructors.

\subsubsection{Differences between Weak and Strong Uncertainty Avoidance Societies}

This parameter deals with the degree of acceptance or tolerance regarding unstructured situations. The German participants were surprised by the strong tolerance of the Moroccans, which broke down certain stereotypes from the German side. The Moroccans talked about "Oktoberfest", a festival held in Bavaria. They also talked about free male/female relationships in European society. These relationships are acceptable to Europeans even in Moroccan society, but they remain unacceptable by Moroccans in their country, due essentially to their religious background.

The notion of time is more respected in northern society in general. Missing an appointment is not tolerated. During the synchronous sessions, this parameter appeared to be more strongly considered for all the participants regardless of their nationality. If they were late, the students made apologies.

\subsubsection{Differences between Collectivist and Individualist Societies}

The collectivism/individualism parameter was expressed by each side of the Mediterranean very differently, as they agreed on some aspects but differed on others. When talking about celebrations or mourning, for example, Moroccans seem to be more anchored to the family sphere where any detail of organization or action takes family principles and advice as fundamental. This was perceived for both groups collectively or individually from the beginning of the course. The activity on the Padlet wall, of sharing ideas about the opposite foreign culture, produced some questions for each participant. By learning about introspection and discussing this element in the second Zoom meeting, the participants came up with clearer opinions of their own.

\subsubsection{Differences between Feminine and Masculine Societies}

This point was very often raised in different situations in the course. Moroccans said that their society is more masculine than feminine and that this has to be changed. Female Moroccan participants were asked how they will handle cultural shocks when they go abroad (Padlet). This shows how deeply that dimension still has to be developed in their inner consciousness (introspection). By the end of the course, the female Moroccan students were aware of this (fourth Zoom meeting).

On the German side, as men and women are treated equally in their society, they are free to travel, study, or live their lives as they wish without any difference between the two genders.

Being made aware of this parameter was quite interesting for all the participants, and this is something they expressed. 


\subsubsection{Differences between Short- and Long-Term-Oriented Societies}

This dimension was expressed and cited by all the participants equally in different ways. Both sides shared their wishes to live as equals in the world, working and trying to improve their lives and those of their families. They agree that their future lives depend on day-to-day work and the amount of energy they put into it. For them, studying hard is the way to get a good job and live quietly.

\subsubsection{Differences between Indulgent and Restrained Societies}

In the discussions on WhatsApp and the exchanges on the Padlet walls, we noticed small differences between Moroccan and German students. Both societies seek pleasure in their lives. However, the Moroccans seem to be a little bit less indulgent than the Germans. We observed only some small differences related to religious directives and sexuality concerns; the other parameters are nearly equal.

However, our global observation is that the participants felt more confident as the course progressed. At the start, they were slightly more cautious when talking and expressing their emotions or opinions. By the end, they expressed a more positive attitude, higher optimism, more personal life control, and the importance of being open.

To summarise, the participants were able to learn about and implement cultural and intercultural knowledge. The practical implementation of this knowledge contributed to the development of their cultural skills [49]. We can assume that by the end of the $\mathrm{VE}$, the participants had gained an awareness of their home culture through a simple exercise of introspection, they had learned about another culture and discarded certain stereotypes when exchanging reflections in synchronous or asynchronous sessions, and they had communicated and shown openness to respectful dialogue.

\section{Conclusions and Perspectives}

VE is increasingly present in collaborative teaching practices between different cultures [63]. VE was initially introduced as an experiment to promote the enhancement of foreign language learning [64]. Then it was identified as a more complex process that requires supplementary exploration. Reflection on the perceived cultural differences between learners as well as the lack of digital literacy has to be thoroughly considered before setting up any VE experiment. Thus, the research in this field has pushed investigations even further in adapting specific pedagogies to this kind of scenario [63].

In this work, we aimed to describe a VE model that was pedagogically designed to meet the needs of students for eventual mobility (physical). The objectives of this exchange were stated as the improvement of language, digital, and cultural knowledge. The practice of this knowledge will undoubtedly lead to the acquisition of skills necessary for studying or working internationally. We talk about global competencies.

The pedagogical model was based on flexible content management, continuous monitoring and tutoring, a variety of digital tools, and an openness to working in or outside the LMS platform. The work on designing the model was crucial for the accomplishment of the VE objectives.

In our analysis of the exchanges, the completed activities, and the participation and the involvement of the learners, we noted:

- Some improvement in students' oral and written English language skills.

- Students' mastery of new digital tools for sharing, collaboration, and communicating.

- A clear awareness of the cultural parameters of the Hofstede model, starting from personal introspection to the perception of the clash of cultures with the projection of living in a culturally distant society.

Putting this into practice no doubt led to participants gaining language, digital, and cultural competencies.

The experience was crowned by the allocation of digital badges to the learners who actively participated in the exchange and assisted in the validation session held by the UNICollaboration Project team [65]. This could be a very strong motivation for future 
participants, as they can include it in their experience when looking for transnational work or studies.

That said, although the pedagogical team was satisfied with the completion of the course objectives, the amount of time and workload was very significant. We also pointed out that the period of four plus one weeks was very tight for the quantity of information transmitted or exchanged, which made the work more tedious for both the teaching team and the learners. It would be better to generalise the experience on a large scale and measure the acquisition of the competencies in more depth. One other parameter to consider is to include this kind of learning in the learning curricula to benefit from the technical and pedagogical support of the universities.

As a perspective on this work, another more extensive session of this VE started in early 2020, and one member of the team is following it closely. It is accredited (ECTS) and will be implemented for a longer period. A third experience, based on MOOCs for a larger audience, is being studied.

Author Contributions: For this article, contributions have been done in agreement between authors as follows. Conceptualization, S.M. and J.H.; methodology, S.M. and R.B.; software, S.M.; validation, S.M., J.H., R.B., K.B. and D.B.; formal analysis, S.M.; investigation, S.M.; resources, S.M., J.H. and R.B.; data curation, S.M.; writing —original draft preparation, S.M. and J.H.; writing—review and editing, S.M., J.H., R.B., K.B. and D.B.; visualization, S.M.; supervision, R.B., K.B. and D.B. All authors have read and agreed to the published version of the manuscript.

Funding: This research received no external funding.

Institutional Review Board Statement: Not applicable.

Informed Consent Statement: Informed consent was obtained from all subjects involved in the study.

Data Availability Statement: The data presented in this study are available on request from the corresponding authors.

Acknowledgments: Special thanks to the UNICollaboration team and former trainers for their collaboration and support.

Conflicts of Interest: The authors declare no conflict of interest.

\section{References}

1. Pécoud, A.; de Guchteneire, P.; Guchteneire, P.F.A. Migration without Borders: Essays on the Free Movement of People; Berghahn Books: New York, NY, USA, 2007; ISBN 978-1-84545-360-2.

2. Czaika, M.; Orazbayev, S. The Globalisation of Scientific Mobility, 1970-2014. Appl. Geogr. 2018, 96, 1-10. [CrossRef]

3. Suarez-Orozco, M. Learning in the Global Era: International Perspectives on Globalization and Education; University of California Press: Oakland, CA, USA, 2007.

4. Landis, D.; Albert, R.D. (Eds.) Handbook of Ethnic Conflict; International and Cultural Psychology; Springer: Boston, MA, USA, 2012; ISBN 978-1-4614-0447-7.

5. Department of Economic and Social Affairs. Transforming Our World: The 2030 Agenda for Sustainable Development. Available online: https: / /sdgs.un.org/2030agenda (accessed on 13 April 2021).

6. World Economic Forum New Vision for Education. Unlocking the Potential of Technology. Available online: http://www3 .weforum.org/docs/WEFUSA_NewVisionforEducation_Report2015.pdf (accessed on 22 May 2020).

7. Xu, X.J.; Li, Y. Building Cross-Cultural Competence Model for Expatriate Managers in Low-to-Middle Levels. In Proceedings of the 2012 International Symposium on Management of Technology (ISMOT), Hangzhou, China, 8 November 2012 ; pp. 522-526.

8. Ayers, J. Competence Literate but Context Lacking? Investigating the Potential of Study Abroad Programs to Promote Sustainability Competence Acquisition in Students. Sustainability 2020, 12, 5389. [CrossRef]

9. Çiftçi, E.Y.; Savaş, P. The Role of Telecollaboration in Language and Intercultural Learning: A Synthesis of Studies Published between 2010 and 2015. ReCALL 2018, 30, 278-298. [CrossRef]

10. Friedrichs, J. An Intercultural Theory of International Relations: How Self-Worth Underlies Politics among Nations. Int. Theory 2016, 8, 63-96. [CrossRef]

11. Oren, A.; Mioduser, D.; Nachmia, R. The Development of Social Climate in Virtual Learning Discussion Groups. Int. Rev. Res. Open Distance Learn. 2002, 3. [CrossRef]

12. Rychen, D.S.; Salganik, L.H. Definition and Selection of Competencies (DESECO): Theoretical and Conceptual Foundations; Swiss Federal Statistical Office: Neuchatel, Switzerland, 2002.

13. Ramos, G.; Schleicher, A. Global Competency for an Inclusive World; OECD: Paris, France, 2016. 
14. OECD. PISA 2018 Results (Volume VI): Are Students Ready to Thrive in an Interconnected World? OECD: Pisa, Italy, 2020; ISBN 978-92-64-27174-6.

15. O'Dowd, R. From Telecollaboration to Virtual Exchange: State-of-the-Art and the Role of UNICollaboration in Moving Forward. J. Virtual Exch. 2018, 1, 1-23. [CrossRef]

16. Vinagre, M. Developing Teachers' Telecollaborative Competences in Online Experiential Learning. System 2017, 64, 34-45. [CrossRef]

17. European Union. EACEA Debate Exchange Team Leader Manual. Available online: https://europa.eu/youth/sites/default/ files/eyp/eve/attachments/en._debate_exchange_-_team_leaders_manual_-_april_2019.pdf (accessed on 1 January 2020).

18. Morgan, T.; Carey, S. From Open Content to Open Course Models: Increasing Access and Enabling Global Participation in Higher Education. Int. Rev. Res. Open Distance Learn. 2009, 10. [CrossRef]

19. O'Dowd, R. Telecollaborative Networks in University Higher Education: Overcoming Barriers to Integration. Internet High. Educ. 2013, 18, 47-53. [CrossRef]

20. About Erasmus+ Virtual Exchange. Available online: https://europa.eu/youth/node/54451_en (accessed on 1 September 2019).

21. About Virtual Exchange. Available online: https:// europa.eu/youth/erasmusvirtual/about-virtual-exchange_en (accessed on 1 September 2019).

22. Global Flow of Tertiary-Level Students. Available online: http://uis.unesco.org/en/uis-student-flow (accessed on 14 March 2021).

23. European Commission. The European Higher Education Area in 2018: Bologna Process Implementation Report; European Commission: Brussels, Belgium, 2018; ISBN 978-92-9492-739-2.

24. Ballatore, M.; Ferede, M.K. The Erasmus Programme in France, Italy and the United Kingdom: Student Mobility as a Signal of Distinction and Privilege. Eur. Educ. Res. J. 2013, 12, 525-533. [CrossRef]

25. Rapport d'activités 2018, Résultats Erasmus+2014-2018. Available online: http://www.agence-erasmus.fr/docs/2773_ra-2018 .pdf (accessed on 1 September 2019).

26. Enarson, H.; Drucker, P.F. Innovation in Higher Education. J. High. Educ. 2021, 31, 495-501. [CrossRef]

27. Tierney, W.G.; Lanford, M. Conceptualizing Innovation in Higher Education. In Higher Education: Handbook of Theory and Research; Paulsen, M.B., Ed.; Springer: Cham, Switzerland, 2016; Volume 31, pp. 1-40, ISBN 978-3-319-26828-6.

28. Cabedo, L.; Royo, M.; Moliner, L.; Guraya, T. University Social Responsibility towards Engineering Undergraduates: The Effect of Methodology on a Service-Learning Experience. Sustainability 2018, 10, 1823. [CrossRef]

29. Thomas, I. Special Issue-Pedagogy for Education for Sustainability in Higher Education. Sustainability 2014, 6, 1705-1708. [CrossRef]

30. O'Dowd, R. Emerging Trends and New Directions in Telecollaborative Learning. CALICO J. 2016, 33, 291-310. [CrossRef]

31. Louhiala-Salminen, L.; Kankaanranta, A. Professional Communication in a Global Business Context: The Notion of Global Communicative Competence. IEEE Trans. Profess. Commun. 2011, 54, 244-262. [CrossRef]

32. Byram, M. Conceptualizing Intercultural (Communicative) Competence and Intercultural Citizenship. In The Routledge Handbook of Language and Intercultural Communication; Routledge: Abingdon, UK, 2012; pp. 85-97.

33. Byram, M.; Zarate, G. Defining and Assessing Intercultural Competence: Some Principles and Proposals for the European Context. Lang. Teach. 1996, 29, 239-243. [CrossRef]

34. Ai, B.; Cui, C.; Wang, L. Language, Identity, and Transnational Communication: Chinese Business Expatriates in Africa. IEEE Trans. Profess. Commun. 2019, 62, 178-191. [CrossRef]

35. Lai, J.; Shen, T.; Hsieh, M. The Analysis of the Relationship between Cultural Factor and Second Language Acquisition. In Proceedings of the 2016 International Conference on Advanced Materials for Science and Engineering (ICAMSE), Tainan, Taiwan, 12-13 November 2016; pp. 412-415.

36. Nascimbeni, F.; Burgos, D.; Aceto, S.; Wimpenny, K.; Maya, I.; Stefanelli, C.; Eldeib, A. Exploring Intercultural Learning through a Blended Course about Open Education Practices across the Mediterranean. In Proceedings of the 2018 IEEE Global Engineering Education Conference (EDUCON), Tenerife, Spain, 17-20 April 2018; pp. 285-288.

37. Zumbihl, H. Cadre théorique et méthodologique d'une étude sur l'acquisition de la compétence de médiation culturelle en milieu universitaire. ASP 2004, 125-134. [CrossRef]

38. Tu, J.-C.; Zhang, X.-Y.; Chiu, S.-P. Assessing the Impact of Cultural Intelligence on Sustainable Career Competitive Advantage for Students in College of Design. Sustainability 2020, 12, 10. [CrossRef]

39. Jager, S.; Meima, E.; Oggel, G. Oral Proficiency Teaching with WebCEF and Skype: Scenarios for Online Production and Interaction Tasks. Lang. Learn. High. Educ. 2013, 2. [CrossRef]

40. Lee, L. Promoting Intercultural Exchanges with Blogs and Podcasting: A Study of Spanish-American Telecollaboration. Comput. Assist. Lang. Learn. 2009, 22, 425-443. [CrossRef]

41. García-Sánchez, S.; Rojas-Lizana, S. Bridging the Language and Cultural Gaps: The Use of Blogs. Technol. Pedagog. Educ. 2012, 21, 361-381. [CrossRef]

42. Knight, S. Effective Practice in a Digital Age. Available online: http://repository.jisc.ac.uk/6004/1/effectivepracticedigitalage.pdf (accessed on 1 September 2019).

43. Fuchs, C. "Are You Able to Access This Website at All?"-Team Negotiations and Macro-Level Challenges in Telecollaboration. Comput. Assist. Lang. Learn. 2016, 29, 1152-1168. [CrossRef] 
44. Barth, M.; Burandt, S. Adding the "e-" to Learning for Sustainable Development: Challenges and Innovation. Sustainability 2013, 5, 2609-2622. [CrossRef]

45. Peiser, G. Overcoming Barriers: Engaging Younger Students in an Online Intercultural Exchange. Intercult. Educ. 2015, 26, 361-376. [CrossRef]

46. Hauck, M.; Müller-Hartmann, A.; Rienties, B.; Rogaten, J. Approaches to Researching Digital-Pedagogical Competence Development in VE-Based Teacher Education. J. Virtual Exch. 2020, 3, 5-35. [CrossRef]

47. Salomão, A.C.B.; Viana da Silva, E. The Application of the Global Competence Matrix in a Virtual Exchange Program with US and Brazilian Students. J. Virtual Exch. 2020, 3, 1-12. [CrossRef]

48. Ferreira-Lopes, L.; Bezanilla, M.J.; Elexpuru, I. Integrating Intercultural Competence Development into the Curriculum through Telecollaboration. A Task Sequence Proposal for Higher Education. Rev. Edu. Distancia 2018. [CrossRef]

49. Leeds-Hurwitz, W. Intercultural Competences: Conceptual and Operational Framework. 2013. Available online: https://unesdoc. unesco.org/ark:/48223/pf0000219768 (accessed on 1 September 2020).

50. Klieme, E.; Hartig, J.; Rauch, D. The Concept of Competence in Educational Contexts. Assess. Competencies Educ. Contexts 2008, $3,22$.

51. Le Deist, F.D.; Winterton, J. What Is Competence? Hum. Resour. Dev. Int. 2005, 8, 27-46. [CrossRef]

52. Braxton, S.; Bronico, K.; Looms, T. Instructional System Design (ISD): Using the ADDIE Model; George Washington University: Washington, DC, USA, 2000.

53. Salmon, G. E-Tivities: The Key to Active Online Learning; Routledge: Abingdon, UK, 2013.

54. Karsenti, T.; Savoie-Zajc, L. La Recherche en Éducation, Etapes et Approches? 4th ed.; Les Presses de l'Université de Montréal: Montreal, QC, Canada, 2018; ISBN 978-2-7606-3933-1.

55. Mulhall, A. In the field: Notes on observation in qualitative research. J. Adv. Nurs. 2003, 41, 306-313. [CrossRef] [PubMed]

56. Avgousti, M.I. Intercultural communicative competence and online exchanges: A systematic review. Comput. Assist. Lang. Learn. 2018, 31, 819-853. [CrossRef]

57. Korzh, R.; Peleschyshyn, A.; Syerov, Y.; Fedushko, S. The Cataloging of Virtual Communities of Educational Thematic. Webology 2014, 11, 16.

58. Bueno-Alastuey, M.C.; Kleban, M. Matching Linguistic and Pedagogical Objectives in a Telecollaboration Project: A Case Study. Comput. Assist. Lang. Learn. 2016, 29, 148-166. [CrossRef]

59. Kleban, M.; Bueno-Alastuey, M.C. Creating Pedagogical Knowledge through Electronic Materials in a Telecollaboration Project for Pre-Service Teacher Trainees. In WorldCALL: Sustainability and Computer-Assisted Language Learning; Gimeno, A., Levy, M., Blin, F., Barr, D., Eds.; Advances in Digital Language Learning and Teaching; Bloomsbury Academic: London, UK, 2016; pp. 39-52, ISBN 978-1-4742-4832-7.

60. Vuorikari, R.; Punie, Y.; Carretero, S.; Pujol Priego, L.; Kluzer, S.; Cabrera, M.; O’Keeffe, W.; European Commission; Joint Research Centre. DigComp into Action, Get Inspired Make It Happen a User Guide to the European Digital Competence Framework; Publications Office of the European Union: Luksemburg, 2018.

61. Sevilla Pavón, A.; Haba Osca, J. “Te das cuenta de que el mundo puede ser tan distinto y similar al mismo tiempo": Telecolaboración y desarrollo de la competencia intercultural en la educación superior. Didáctica 2016, 28, 263-284. [CrossRef]

62. Hofstede, G. Dimensionalizing Cultures: The Hofstede Model in Context. Online Read. Psychol. Cult. 2011, 2. [CrossRef]

63. O'Dowd, R.; Sauro, S.; Spector-Cohen, E. The Role of Pedagogical Mentoring in Virtual Exchange. TESOL J. 2019, 54, 146-172. [CrossRef]

64. Abraham, L.B.; Williams, L. Expanding Discourse Options through Computer-Mediated Communication: Guiding Learners Toward Autonomy. Foreign Lang. Ann. 2011, 44, 626-645. [CrossRef]

65. UNICollaboration Open Badges for Virtual Exchange. Available online: https://www.unicollaboration.org/index.php/2020/02/ 20/open-badges-for-virtual-exchange/ (accessed on 20 February 2020). 